\title{
El Catálogo General del Patrimonio Histórico Andaluz en el Campo de Gibraltar
}

La comarca del Campo de Gibraltar está conformada por cinco municipios según la demarcación de paisajes culturales del IAPH: Algeciras, Los Barrios, Castellar de la Frontera, La Línea de la Concepción y San Roque. En esta zona nos encontramos 71 bienes patrimoniales inscritos en el Catálogo General del Patrimonio Histórico Andaluz (CGPHA), además de dos zonas de servidumbre arqueológica, que por su propia naturaleza quedan fuera del catálogo. Si los clasificamos por la figura legal que les da protección, hallamos 63 bienes de interés cultural (BIC), y ocho de catalogación general, de los cuales cuatro están relacionados con arquitectura del movimiento moderno.

\section{Bienes de Interés Cultural}

\begin{tabular}{lc}
\hline Tipología & Bienes \\
\hline Monumento: & \\
\hline *Otros & 7 \\
\hline *Arte Rupestre & 28 \\
\hline *Arquitectura militar & 20 \\
\hline Zona arqueológica & 5 \\
\hline Conjunto histórico & 3 \\
\hline Total & 63
\end{tabular}

Esta comarca, al conformarse por municipios cuya ubicación favorece el control entre dos mares y dos continentes, tiene un fuerte carácter fronterizo, lo cual se puede apreciar por la importante cantidad de arquitectura militar que se encuentra en dicha área, destacando las torres almenaras marinas a lo largo de su costa, enclaves estratégicos en los límites Mediterráneo-Atlántico y Europa-África.

En el Campo de Gibraltar se han hallado sitios arqueológicos relacionados con el Paleolítico Inferior en casi todos los términos municipales, los cuales han aportado gran cantidad de información a través de sus materiales líticos. Pero lo que realmente destaca cuantitativa, además de patrimonialmente, es el patrimonio protegido referido a lo que se ha denominado arte sureño', el conjunto de pinturas rupestres ubicadas en cuevas o abrigos, caracterizadas por el mismo patrón de asentamiento, y datadas en diferentes épocas que van desde el Paleolítico a la Edad de Bronce.

Entre los expedientes de protección que afectan al patrimonio histórico andaluz, habría que hacer una mención especial al caso de Carteia en el término municipal de San Roque. La ciudad púnica-romana fue declarada conjunto histórico-artístico por Decreto 2352/1968, de 16 de agosto, al amparo de la Ley del Tesoro Artístico Nacional de 13 de mayo de 1933. El CGPHA tiene una holgada memoria (su primer expediente inscrito data de 1856: Monasterio de Santa Maria de la Rábida), y su historia es también la de la protección. La descripción de los límites de este conjunto histórico aparece en el Decreto: "esta declaración comprenderá dos zonas: la zona arqueológica propiamente dicha [1, en el plano adjunto] constituida por el espacio incluido dentro del antiguo recinto amurallado más una faja de setenta metros [2] de terreno exterior al mismo, asi como las termas y ruinas contiguas a la costa, y la urbana [3], de ordenación especial formada por el caserío y espacio de fábrica de salazón, situada entre la zona arqueológica y el río Guadarranque". Hoy en día podría resultar complejo diferenciar si esta segunda zona, la denominada urbana, forma parte del bien o sería una definición más próxima al actual concepto de entorno. No obstante, autores como Gabriel Alomar a mediados de 1960 (número primero de las Instrucciones para la defensa de los Conjuntos HistóricoArtísticos) ofrecieron aclaraciones sobre lo que por el entonces Ministerio de Educación Nacional entendia como zonas de respeto o de ordenación especial, siendo evidente que no pueden equipararse a nuestra definición de entorno. De este modo, la ciudad de Carteia posee un único polígono de protección que ha de ser construido en tres partes a semejanza de las piezas de un puzzle. Su área de protección sigue plenamente vigente, aún a pesar de que hoy en día hubiéramos elegido precisamente la tipología que el Decreto de 1964 parecía anunciar antes de su definición oficial en la Ley 16/1985, la de zona arqueológica.

Retomando el gran carácter fronterizo de esta tierra, ha de aclararse que no sólo en la Edad Media se erigieron construcciones militares como fortalezas y torres vigias, sino que en época moderna y contemporánea, a lo largo del litoral gaditano, se construyeron edificaciones relacionadas con el control del territorio, como es el caso de la red de búnkeres construidos durante el transcurso de los conflictos bélicos de la guerra civil española y la Segunda Guerra Mundial, y para los que la Dirección General de Bienes Culturales tiene abierto expediente para inscribirlos de forma colectiva en el CGPHA.

El Catálogo General del Patrimonio Histórico Andaluz está abierto a la consulta pública en la página web de la Consejería de Cultura, dentro del área de Bienes Culturales: http://www.juntadeandalucia.es/cultura

\section{Alfonso Montejo Ráez}

Olga Viñuales Meléndez

Servicio de Protección del Patrimonio Histórico

Dirección General de Bienes Culturales

Nota

www.arte-sur.com
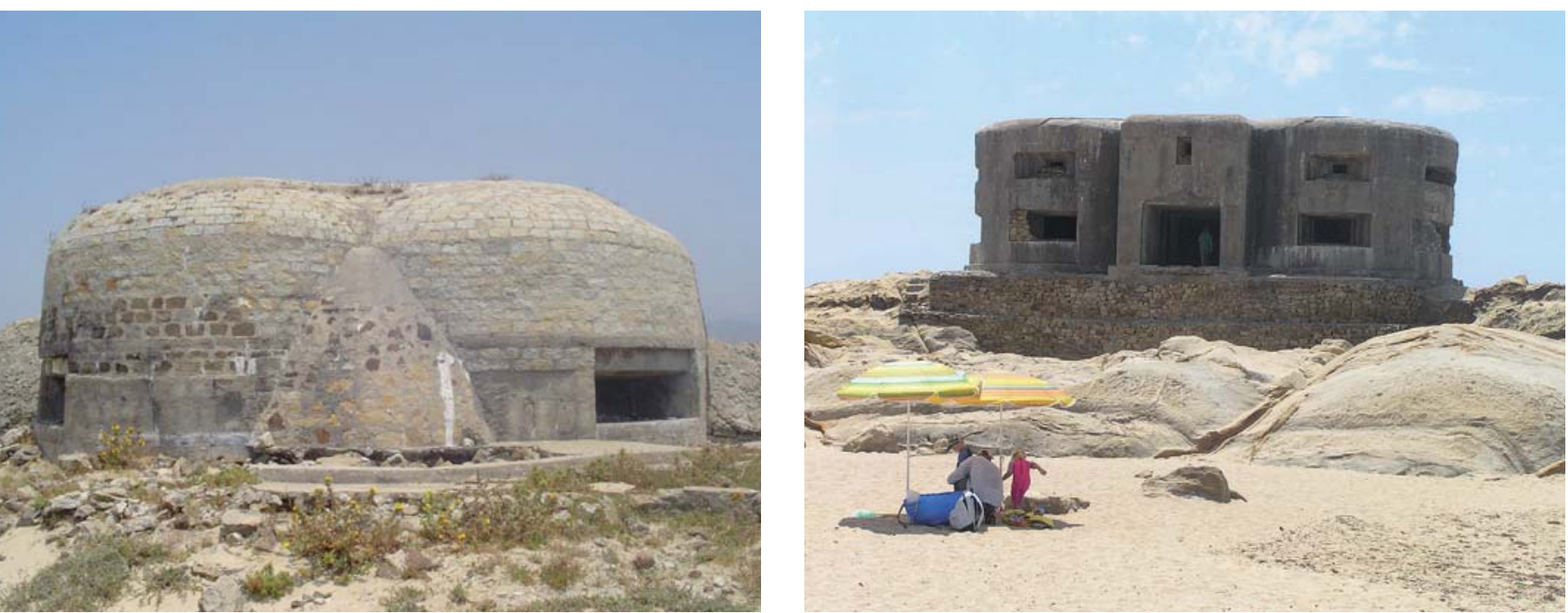

Búnkeres en la playa de los Lances (izquierda) y en la playa del cabo de la Plata Fołos: Dirección General de Bienes Culturales (Ángel Sáez Rodríguez, Pedro Gurriarán Daza, Alfonso Escuadra Sánchez. Yamur. Arquitectura y Arqueología SL) 

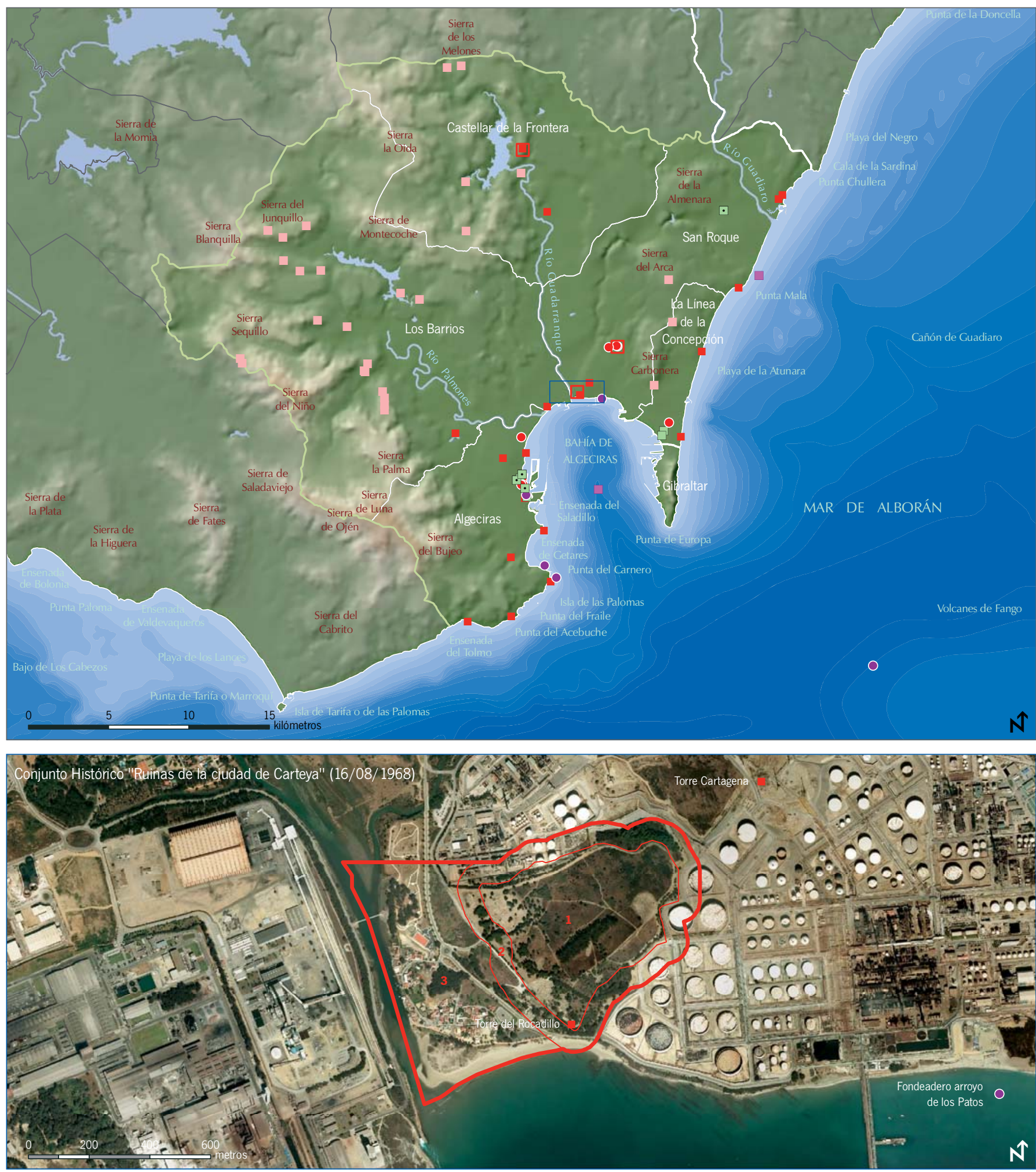

Bien de Interés

Cultural

$\square$ Conjunto Histórico
El Catálogo General del Patrimonio Histórico Andaluz en el Campo de Gibraltar

Bien de Catalogación General $\square$

Arquitectura del Movimiento Moderno •

Zona de Servidumbre Arqueológica

Cartografia base: Datos Espaciales de Andalucia 1:100.000, Ortofotografia digital en color de Andalucia 1:10.000, Instituto de Cartografia de Andalucia, 2009 